\title{
Cost-effectiveness analysis of greenhouse dehumidification and integrated pest management using air's water holding capacity-a case study of the Trella Greenhouse in Taizhou, China
}

\author{
Yang Tianning ${ }^{1}$, Xiaohan $\mathrm{Ma}^{2,3 *}$ \\ ${ }^{1}$ Qingdao No.2 Middle School of Shandong Province, 266000 Qingdao, China \\ ${ }^{2}$ Institute of Coastal Environmental Pollution Control, Key Laboratory of Marine Environment and Ecology, Ministry of Education, \\ Ocean University of China, 266100 Qingdao, China
}

${ }^{3}$ College of Environmental Science and Engineering, Ocean University of China, Qingdao 266100, China

\begin{abstract}
Greenhouse technology is becoming an indispensable and feasible solution for modern crop production methods. Technological progress has reduced the impact of severe weather conditions on greenhouse crop yields in high temperature climate. Cooling and dehumidifying are the key to ensure the required temperature and humidity range inside the greenhouse. The purpose of this work is to evaluate the dehumidification technologies used in the agricultural industry. The theoretical and practical aspects of greenhouse cooling technology are shown: working principles, conditions and performance. The primary humidity control method utilized in greenhouses is evaporative cooling by using air's water holding capacity. According to the experimental results, the quantitative analysis was carried out from the perspective of energy and cost, which demonstrated that the evaporative cooling fan-pad system was also an effective method of greenhouse cooling in humid climate. This work would provide technical support or the optimisation of the energy management of greenhouses in humid climates and recommend the mathematical model in future work.
\end{abstract}

\section{Introduction}

Greenhouse technology is becoming an ever increasingly essential and feasible solution for modern crop production technology. Technological progress has reduced the impact of severe weather conditions on greenhouse crop yields in high temperature climate. However, in the daytime with strong solar radiation, the temperature inside the greenhouse was higher than that the ambient temperature due to the absorption of solar radiation, thus, the leaves of plants were easily infected by fungi. Poor growth and disease of plants could cause plant death, which further leads to the decline of crop yield and quality and serious economic losses. In order to build an appropriate growing environment, cooling technologies were indispensable and must be constructed. It plays a crucial role in the greenhouse, particularly in hot weather.

The climate of Taizhou is subtropical monsoon climate, high temperature in summer with more rain, mild winter with less rain. The greenhouse needs to be dehumidified in order to the good growth of plants and the prevention of fungal diseases in the Trella Greenhouse in Taizhou, China. Currently, Trella has three ways to cool the greenhouse. The first is that vents on the roof and walls of the greenhouse were opened to dissipate the hot air. It depends on the natural circulation of air and low outdoor temperature [1]. However, the outdoor temperature in Taizhou in July and August was very high, the air vent was very small, and the vent was often closed because of rain or strong sunlight. This method was not conducive to reducing the temperature and humidity of the greenhouse. The second is that part of the greenhouse was covered with shade to stop the heating. This may be detrimental to plants that need sufficient sunlight to grow. The third one is to reduce the greenhouse temperature through evaporative cooling [2]. When the water evaporates, the heat was carried away from the air, resulting in temperature reduction. Nevertheless, the outside air was very humid in Eastern China, it means that a small amount of water was evaporated into the air by the evaporative-cooling system. The effect of above-mentioned mitigation technologies was very limited. The temperature and humidity in the greenhouse were still very high, and the plant surface was moist for a long time, which made the plants easy to be infected with fungal diseases [3]. So as to overcome the problem, air's water holding capacity was utilized for Trella greenhouse dehumidification.

Because of the high temperature and humidity indoor and outdoor in the daytime, the capacity of evaporative cooling was limited. The experiment of greenhouse 
humidity reduction in Taizhou was carried out at night. When the outdoor temperature drops at night, the air temperature in the greenhouse is raised by heater, and the hot air will hold more moisture. Afterwards the hot air in the greenhouse was removed to remove the moisture in the greenhouse. Evaporative cooling dehumidification had to pay a certain cost by installing heater, exhaust fan, and consuming natural gas in the greenhouse. However, we assume that plants will no longer be affected by diseases and crops will grow better after the greenhouse is heated and dehumidified. High productivity and high-quality crops will bring more economic benefits, and the warming of greenhouse will probably obtain a high level of return on investment. the Trella Greenhouse Humidity Reduction.

The aims of this study were (1) to evaluate the performance of evaporative cooling by using air's water holding capacity in greenhouses in a humid climate; (2) to explore the cost of warming up and dehumidifying the greenhouse air.

\section{Materials and methods}

\subsection{Research Site}

The experiment was conducted in Trella Greenhouse, Taizhou, China. Taizhou is located in East China, where summer is hot and humid.

\subsection{Materials}

There are 10 natural gas heaters and 20 exhaust fans in the greenhouse. The output power of natural gas heater is $272,971 \mathrm{BTU} \cdot \mathrm{hr}^{-1}$. The total output of the exhaust fan is 1.25 ventilation per minute. The environmental meteorological data of the greenhouse was recorded from July 1 to August 31, 2019 at 2:00, 6:00, 18:00 and 22:00 every day, including the changing outside temperature, radiation intensity, air temperature, and relative humidity $(R H)$.

\subsection{Experimental design}

The air temperature of the greenhouse was raised through the natural gas heater. Heating-purging cycle runs 4 times per hour from $9 \mathrm{pm}$ to 4 am (July to August). The warm air and moisture in the greenhouse were removed through the exhaust fan, which was blown 1.25 times per minute and operated for 2 minutes. When warm air was removed, cold air can be drawn in the greenhouse.

\subsection{Data collection and analysis}

\subsubsection{Calculate Dew Point}

According to the difference of greenhouse temperature and $R H$, the dew point in the greenhouse can be calculated by function (1).

$$
T_{d}=T-[(100-R H) / 5]
$$

Where $T_{d}$ represents the dew point; $T$ and $R H$ are temperature and relative humidity inside the greenhouse.

\subsubsection{Calculate BTUs}

The weight of air and air volume in greenhouse are $1.2041 \mathrm{~kg} \mathrm{~m}^{-3}$ and $1.2041 \mathrm{~kg} \mathrm{~m}^{-3}$, respectively. 0.5291 BTU can increase the temperature of $1 \mathrm{~kg}$ of air by $0.555556{ }^{\circ} \mathrm{C}$. Heat required to increase $n{ }^{\circ} \mathrm{C}$ could be fitted by function (2).

$$
H=[(\mathrm{W} * \mathrm{~V} 0.5291 \mathrm{BTU}) / 0.555556] * n
$$

Where $H$ is the heat needed to increase $n{ }^{\circ} \mathrm{C}$ in greenhouse; $W$ is the weight of the air; $V$ is the air volume of the greenhouse.

\subsubsection{Heating-Purging Cycle (Minutes)}

According to the total output power of natural gas heater in greenhouse per minute and the heat needed to increase $n{ }^{\circ} \mathrm{C}$ in greenhouse, the heating cleaning cycle is calculated. The calculation function (3) is as follows.

$$
T=H /(10 * \mathrm{P} / 60)
$$

Where $T$ is the heating-purging cycle calculated when the heat needed to increase $n^{\circ} \mathrm{C}$ in greenhouse; $H$ is the heat needed to increase $n{ }^{\circ} \mathrm{C}$ in greenhouse; $\mathrm{P}$ is the output power of each natural gas heater and its value is $272971 \mathrm{BTU} \mathrm{hr}^{-1}$.

\subsubsection{Calculate Cost of Heating \& Venting (Dols.)}

According to the function (4), the cost of increasing $n{ }^{\circ} \mathrm{C}$ in one heating-purging cycle is calculated.

$$
F=(H / 1,000,000 \mathrm{BTU}) * 28.88
$$

Where $F$ is the cost of increasing $n^{\circ} \mathrm{C}$ in one heatingpurging cycle; $H$ is the heat needed to increase $n{ }^{\circ} \mathrm{C}$ in greenhouse, the average price of natural gas for $1,000,000$ BTU is $\$ 28.88$ in the United States.

It is heated for 6 hours every night, and the heating purge cycle runs 4 times per hour. According to the following function (5), the cost of increasing $n{ }^{\circ} \mathrm{C}$ is calculated every night.

$$
F_{E}=F^{*} 6 \text { hours / night } * 4 \text { times / hour }
$$

Where $F_{E}$ is the cost of increasing $n^{\circ} \mathrm{C}$ in greenhouse for one night; $F$ is the cost of increasing $n^{\circ} \mathrm{C}$ in one heating-purging cycle.

There were 62 days in July and August. The total cost of increasing $n{ }^{\circ} \mathrm{C}$ in July and August is calculated according to the following function (6)

$$
F_{T}=F_{E} * 62 \text { days }
$$


Where $F_{T}$ is the total cost of greenhouse to increase $n{ }^{\circ} \mathrm{C}$ in July and August; $F_{E}$ is the cost of increasing $n{ }^{\circ} \mathrm{C}$ in greenhouse for one night.

\section{Results and discussion}

\subsection{High temperatures and high humidity condition will lead to the outbreak of fungal diseases in greenhouse}

Fig. 1a showed the variation of air temperature and $R H$ of the Trella Greenhouse in Taizhou, China from July to August. According to the formula (1) in Section 2.4, the dew point of the greenhouse from July to August was calculated. Fig. $1 \mathrm{~b}$ showed the variation of the dew point of the Trella Greenhouse. From July to August, the outdoor temperature of the greenhouse was $18.8-31.2^{\circ} \mathrm{C}$ with an average temperature up to $23.4{ }^{\circ} \mathrm{C}$. Excessive outdoor temperature, small vents and strong sunlight leaded to very high temperatures in the greenhouse. The indoor temperature of the greenhouse was $21.2-30.5^{\circ} \mathrm{C}$ with an average temperature of $25.3{ }^{\circ} \mathrm{C}$, which exceed about $2{ }^{\circ} \mathrm{C}$ of outdoor temperature. In summer, the greenhouse vents were often closed because of heavy rains and strong sunlight, which would prevent heat and moisture from diffuse outside the greenhouse. Moreover, irrigation and plant transpiration contributed high moisture content in the air of the greenhouse [4]. The average relative humidity in the greenhouse was as high as $96 \%$, and the relative humidity is greater than $90 \%$ during about $90 \%$ of the monitoring period (Fig. 1). Therefore, ventilation alone couldn't reduce the temperature and humidity of the greenhouse effectively. In the greenhouse with high relative humidity, the air contains high moisture, and there is also a lot of moisture on plant leaves. In the high humidity environment, the water on the leaves is difficult to evaporate.

The greenhouse air contained a lot of moisture when the temperature is high during the day. When the temperature in the greenhouse dropped to dew point during the light, water droplets was a condensation of water vapor on the leaves or fruits of plants, resulting in excessive water on the surface of the plant. There were small differences between the dew points and greenhouse temperatures (Fig. 1). Within $77 \%$ of the time, the temperature in the greenhouse dropped less than $1{ }^{\circ} \mathrm{C}$ before reaching the dew points. The air moisture would condense into droplets on the surface of leaves, further increasing the moisture content on the leaves. These leaves remained very moist for a long time. As we all know, microorganisms such as fungi are very fond of wet leaves. The leaves with high humidity were easily infected by Botrytis mold. If plants were exposed to high temperature and humidity for a long time, fungal diseases would spread rapidly. These would lead a largescale outbreak of diseases, especially in the dense plantings and dense leaves. Plants infected with fungal would lead to the death of leaves and even plants in two weeks. As a result, the greenhouse benefits would be reduced. It would also bring huge economic loss. Therefore, the ability of using evaporative cooling to dehumidify and cool the greenhouse was very limited under the environment conditions of high temperature and humidity both inside and outside the greenhouse. Measures must be taken to resolve these problems.

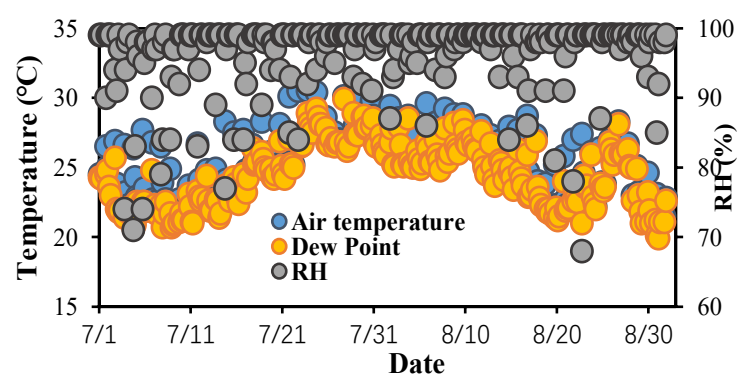

Fig 1. The variation of air temperature、 relative humidity $(\mathrm{RH})$ and Dew Point of the Trella Greenhouse in Taizhou, China.

\subsection{Cost-effectiveness analysis of greenhouse dehumidification using air's water holding capacity}

The air moisture content was closely related to temperature in a humid environment. The temperature exhibited positive correlation with the air's water holding capacity. The air's water holding capacity could be used to dehumidify the greenhouse. We could take the following measures to dehumidify the greenhouse during the light. First, the heater was used to heat the temperature of the greenhouse to prevent the air temperature from falling to the dew point in the greenhouse, and the small droplets condensed on the leaf surface. Then, the warmer air would hold more moisture after raising the temperature of the air. After that, we exhausted the warm air from the greenhouse with an air extractor, thus the moisture in the hot air was also been removed. Therefore, the moisture in the greenhouse could be removed during heating the temperature and purifying the air. The risk of plant growth deterioration and fungal diseases could be significantly reduced by heating and dehumidification, which was conducive to saving costs and increasing profits. The heat, heating cleaning cycle and cost of heating \& marketing for increasing greenhouse temperature by $3{ }^{\circ} \mathrm{C}, 5{ }^{\circ} \mathrm{C}, 8^{\circ} \mathrm{C}$ and $10^{\circ} \mathrm{C}$ were calculated. In addition, the cost per night for each temperature change and the total cost from July to August were calculated in Fig.2, Fig.3 and Fig.4.

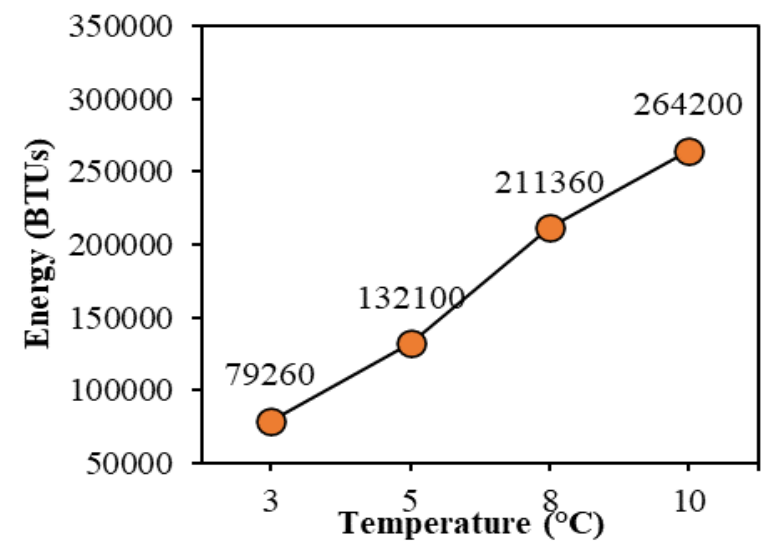

Fig 2. The required energy. 


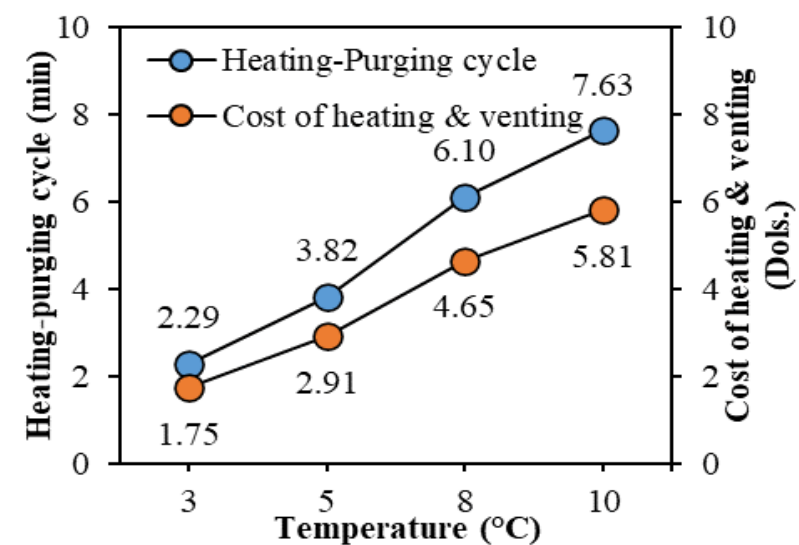

Fig 3. The Heating-purging cycle and the cost of heating \& venting.

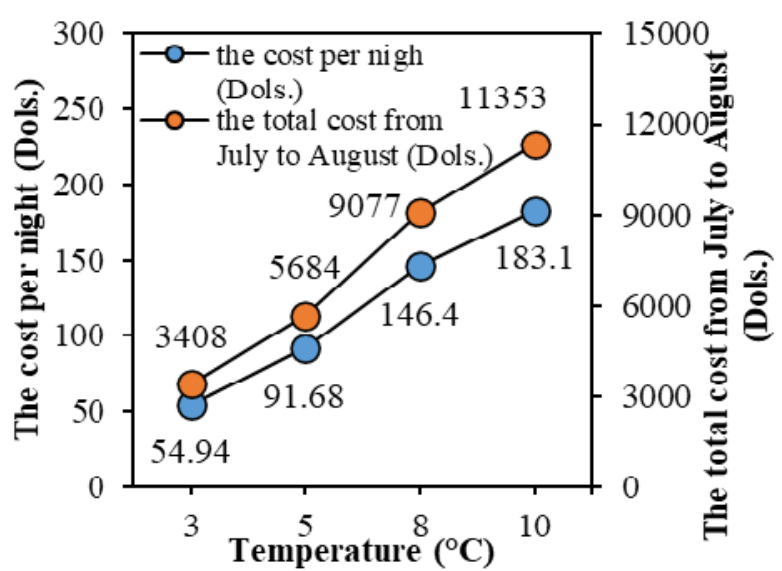

Fig 4. The cost per night and the total cost from July to August.

The cost of the greenhouse increased with the greenhouse temperature rises. It was important to determine the temperature of greenhouse heating. As depicted in Fig. 1, there was a difference between the actual air temperature and dew point in the greenhouse. In the 248 time points monitored, the difference between the actual air temperature and the dew point was within $3{ }^{\circ} \mathrm{C}$ in $92.7 \%$ of the time points. Consequently, the air temperature in the greenhouse was increased by more than $3{ }^{\circ} \mathrm{C}$ through natural gas heaters, which could prevent the water vapor in the greenhouse from condensing into water droplets on the leaves or fruits of plants. Meanwhile, the hot air was discharged from the greenhouse by the fan, and the cold air was allowed to enter the greenhouse during the heating process. At night, the plants and fruits were heated as the temperature in the greenhouse increased. And the cooling rate of plants and fruits was generally slower than that of greenhouse air, which also reduced the risk of condensation. Therefore, the highest profits were obtained when the greenhouse was heated by $3{ }^{\circ} \mathrm{C}$, which was consistent with initial hypothesis.

\section{Conclusions}

In this experiment, air's water holding capacity was utilized to dehumidify Trella greenhouse. In the process of greenhouse management, the application of the information provided by the hygrometer was important for controlling the greenhouse environment. Based on the principle of water and energy transfer process in greenhouse, the temperature of greenhouse should be controlled reasonably to adjust the humidity of greenhouse, so as to save the operating cost of greenhouse. As a greenhouse manager and agronomist, it was necessary to deeply understand the scientific background of greenhouse environment and the relationship between temperature, humidity and energy, and take some effective and cost-effective measures to make greenhouse plants grow in a better environment, higher yield and better quality.

According to the requirements of temperature, humidity, light and other greenhouse climate of plants, a digital psychrometric chart was developed to control horticultural and greenhouse climate, which was integrated into the application program in the following study. The temperature and humidity data inside and outside the greenhouse were also transmitted to the program from time to time to display the dew point and enthalpy data of the greenhouse at any time. It was convenient to view data on computers and/or smartphones, which greatly improved the accuracy and timeliness of greenhouse management.

\section{Acknowledgment}

This study was supported by Shandong Key Research and Development Program-Science and Technology Innovation Project (2018CXGC0304).

\section{References}

1. M. Amani, S. Foroushani, M. Sultan, M. Bahrami, Appl. Therm. Eng 181, 115979 (2020).

2. M. Ghoulem, K.E. Moueddeb, E. Nehdi, R. Boukhanouf, J.K. Calautit, Biosyst. Eng 183, 121150 (2019)

3. W. Spisak, A. Chlebicki, M. Kaszczyszyn, Sci. Rep, 6, 35847 (2016).

4. M.W. Malone, J. Yoder, J.F. Hunter, M.A. Espy, L.T. Dickman, R.O. Nelson, S.C. Vogel, H.J. Sandin, S. Sevanto, Front. Plant Sci 7, 564 (2016). 